\title{
Genetic evidence of widespread dispersal in a parthenogenetic freshwater ostracod
}

\author{
J. A. CHAPLIN*†, \& D. J. AYRE \\ Department of Biological Sciences, University of Wollongong, Wollongong, NSW 2522, Australia
}

\begin{abstract}
We used an hierarchical analysis of allozyme variation to investigate for the freshwater ostracod Candonocypris novaezelandiae the relative contributions of sexual and asexual reproduction to recruitment into 42 local populations and to infer patterns of gene flow within and among four geographical regions (watersheds) in south-eastern Australia. Allele frequency variation among local populations was marked (mean $F_{\mathrm{ST}}=0.228$ ) but showed no regional differentiation. The allele frequency differences among local populations probably reflect the effects of stochastic processes, such as founder events, as well as variation in the success, and hence abundance, of particular clonal genotypes within water-bodies. Indeed, local populations were highly clonal, containing only females and displaying relatively low levels of genotypic diversity. Nevertheless, the distribution of genotypes within and among regions was surprising. The bulk of sampled individuals ( 88 per cent) were represented by just six common genotypes that were shared extensively among local populations and were geographically widespread. Individual samples contained a mean of 4.05 , and up to 10 , distinct four-locus genotypes and overall we detected a total of 26 electrophoretically distinct genotypes. In combination, our results suggest that either the south-eastern Australian populations of $C$. novaezelandiae arose through a recent colonization event (perhaps associated with an expansion of agricultural practices) or there is sufficient continuing gene flow between regions to prevent differentiation. However, the exact contributions of sexual and asexual reproduction to dispersal in this ostracod remain unclear.
\end{abstract}

Keywords: allozyme, clonal reproduction, dispersal, ostracod, parthenogenesis, population structure.

\section{Introduction}

Many passively dispersed species of freshwater microcrustacea have broad geographical distributions that must reflect either the historical or continuing effects of long-distance dispersal. Recent electrophoretic surveys also imply that effective gene flow occurs over large spatial scales but, paradoxically, established neighbouring populations may have only weak genetic connections. Few species have been surveyed over distances greater than 100 $\mathrm{km}$ but these include a sexually reproducing copepod (Boileau \& Hebert, 1991), two cyclically parthenogenetic cladoceran species (Benzie, 1986; Schwartz \& Hebert, 1987) and three species of Daphnia comprising both cyclical and obligate

*Correspondence. E-mail: jchaplin@murdoch.edu.au

†Current address: Biological Sciences, Murdoch University, Murdoch, Western Australia 6150, Australia.

Both authors contributed equally to this paper. parthenogens (Benzie, 1986; Crease et al., 1990; Hebert et al., 1993). These species almost invariably show a pattern of strong microgeographical gene frequency variation but with little additional variation over macrogeographical scales. However, marked subdivision can occur between continents or major ecotones (e.g. Hebert, 1987; Hebert et al., 1993). This microscale heterogeneity coupled with macroscale homogeneity has been linked to the combined effects of multiple founder events and limited gene flow among established local populations (Crease et al., 1990; Boileau \& Hebert, 1991). Manipulative field experiments and studies of the colonization of vacant water-bodies indicate that, at least for some species of Daphnia, this type of genetic structure probably reflects the ready dispersal of clones among water-bodies but with successful colonizations limited by interclonal competition and habitat-dependent selection (see Benzie 1986; Wilson \& Hebert, 1992). 
The extensive belt of agricultural land in southeastern Australia provides the opportunity to examine the genetic consequences of passive dispersal among a large number of recently created artificial water-bodies. These water-bodies are used as water-supply dams for farm animals but also support a range of crustacean species that have probably undergone a recent and dramatic range expansion as a consequence of agricultural activities during the past 200 years. These species include the ostracod Candonocypris novaezelandiae, which consists of two genetically and morphologically distinct forms (large-green and small-brown morphs), each of which is represented by sexually and parthenogenetically reproducing lineages (Chaplin, 1991). The large-green morph is particularly common in southeastern Australia, occurring in a variety of habitats but most commonly in artificial farm ponds and natural water-bodies that are now used for agricultural purposes. The dispersal agents of this ostracod are unknown but wind, fish, water fowl, insects and stream flow have been implicated for other ostracod species (e.g. Proctor, 1964; De Deckker, 1977; Carbonel et al., 1988).

In an earlier study, we showed that 10 populations of the large-green morph of $C$. novaezelandiae in south-eastern Australia each contained only females and a small number of highly replicated 'clonal' genotypes (Chaplin \& Ayre, 1989). We subsequently used isolation experiments to confirm that females from three other such populations reproduced by parthenogenesis, both in the presence and absence of males from a mixed-sex and genotypically diverse population in Western Australia (Chaplin, 1992). These observations, together with its broad geographical distribution in recently created agricultural ponds, imply that in south-eastern Australia $C$. novaezelandiae is an obligate parthenogen with high levels of gene flow connecting its many local populations. However, we currently know little about the interplay between the origin of clones, clonal dispersal and interclonal interactions. It may be that the multilocus genotypes within each local population represent only a small fraction of the variation present in some ancestral source population(s) and/or that parthenogenesis is recently derived or even absent within some populations.

In this study, we use an hierarchical survey of allozyme variation within populations of the largegreen morph of $C$. novaezelandiae in south-eastern Australia to: (i) estimate the relative importance of sexual and asexual reproduction as sources of recruitment within four major watersheds and a range of freshwater habitats; (ii) determine how genetic and genotypic variation is partitioned within and among regions; and (iii) infer the extent of dispersal between neighbouring and distant populations, with and without connecting streams.

\section{Materials and methods}

\section{Collection of specimens}

We collected samples of $C$. novaezelandiae from each of 42 water-bodies (local populations) separated by up to $850 \mathrm{~km}$ (Fig. 1) and distributed among four geographical regions that roughly correspond to defined watersheds. At each water-body, we collected ostracods from a $5 \mathrm{~m}^{2}$ area of the upper $1 \mathrm{~cm}$ of the benthos. Most water-bodies (34 of 42) were located on farms and used as water-supply dams for livestock (Fig. 1).

We sampled most intensively in the AlburyWodonga region and there structured our sampling to investigate the effects of waterflow on the genetic similarity of populations. Within this region, we took samples from 17 water-bodies on the floodplain of the Murray River (Fig. 1). These sites are all occasionally connected by floodwaters (most recently in 1977) and include three sets of sites that comprised water-bodies joined by ephemeral streams that flow as a result of moderate to heavy rainfall (Fig. 1). In an attempt to control for the effects of waterflow, within the Albury-Wodonga region, we also sampled eight water-bodies spanning a similar geographical distance but without floodplain or stream connections (Fig. 1).

Sampling sites within each region were separated by between 10 and $50 \mathrm{~km}$, the exception being that we grouped all sites within $5 \mathrm{~km}$ of the ocean into the Illawarra coastal region, even though one of these sites was located some $300 \mathrm{~km}$ from the others (Fig. 1). Within each region, some sites were separated by less than $1 \mathrm{~km}$ and formed part of a single farm or had ephemeral streams connections. We termed these aggregated clusters of sites 'neighbourhoods' in recognition of the possible importance of streams and livestock that move within a farm as agents for the localized dispersal of $C$. novaezelandiae. Other populations were termed 'isolated'.

\section{Sample sorting and electrophoresis}

We followed the electrophoretic procedures and interpretations described elsewhere (Chaplin \& Ayre, 1989; Chaplin, 1992). We assayed each ostracod for four polymorphic enzymes: arginine phosphokinase (APK, EC 2.7.3.3); mannose-6-phosphate 
Fig. 1 Locations (circles) of 42 sampled populations of Candonocypris novaezelandiae in four geographical regions in south-eastern Australia. Neighbouring sites are joined to a single circle. Sites indicated with a ' $\dagger$ ' are the only ones not regularly used for agricultural purposes. Within the Albury-Wodonga region, open circles indicate sites located on the Murray River floodplain, the outer boundaries of which are indicated approximately by the broken lines.

Neighbouring floodplain populations that are connected by ephemeral streams are joined to relatively large circles.

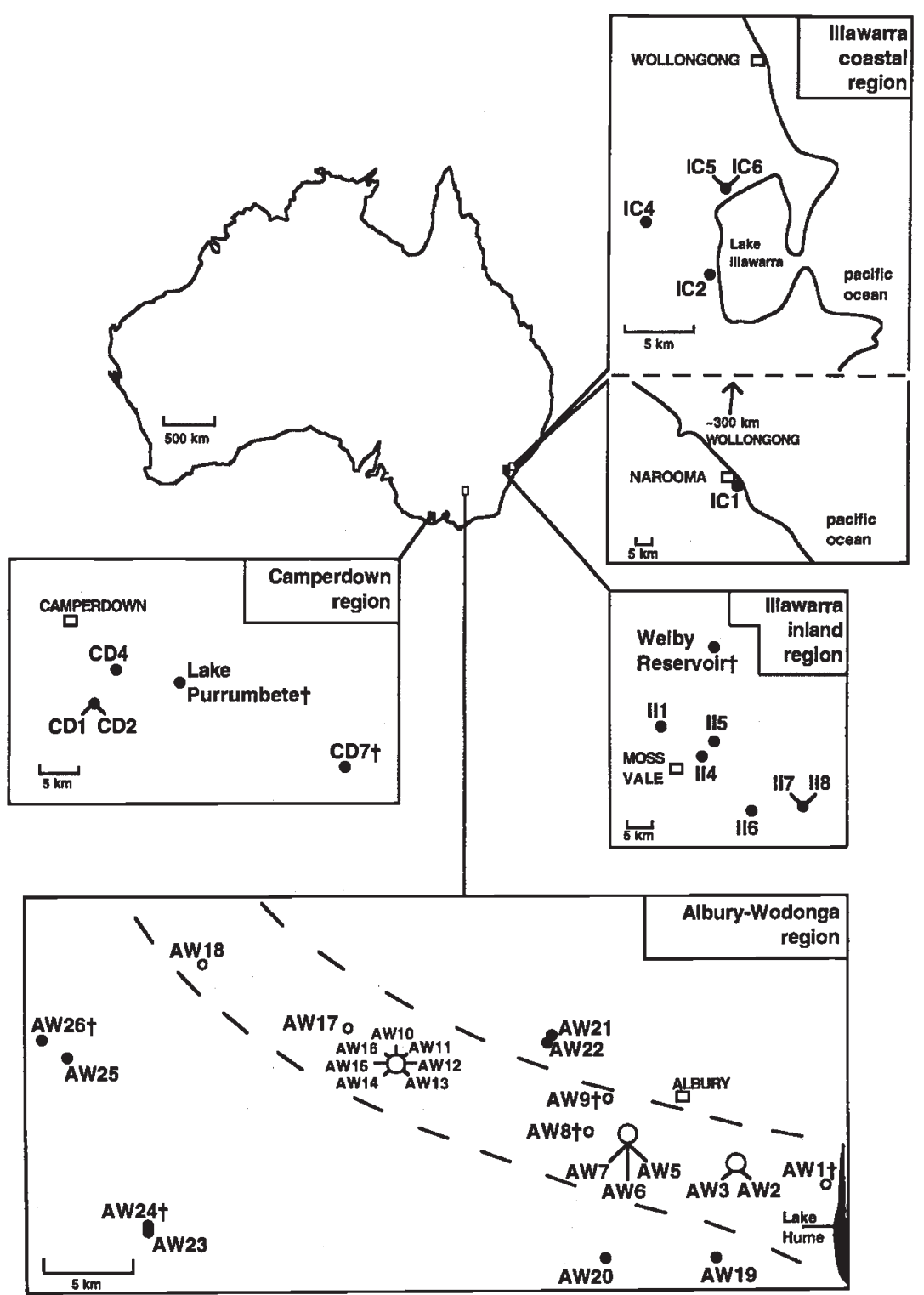

isomerase (MPI, EC 5.3.1.8); phosphoglucomutase (PGM, EC 5.4.2.2) and phosphoglucose isomerase (GPI, EC 5.3.1.9). For each locus, we described each allele in terms of the ratio of the electrophoretic mobility of its allozyme product relative to that of the product of the most common allele.

\section{Data analyses}

We used several approaches to estimate the genetic similarity of populations of $C$. novaezelandiae spread across a range of spatial scales.

We estimated the level of allelic variation among samples as Wright's (1978) standardized genetic variance $\left(F_{\mathrm{ST}}\right)$. Values were expressed as weighted averages across alleles and loci, and adjusted by subtracting the binomial sampling variance for each allele. For each locus, we used a $\chi^{2}$-test $(\mathrm{R} \times \mathrm{C}$ format) to assess the extent of allele frequency variation among samples. To avoid small expected values in these tests, alleles with an overall frequency of less than 0.1 were pooled with the next rarest allele. We used an hierarchical $F_{\mathrm{ST}}$ analysis to partition allelic variation within and among three spatial scales. These scales were neighbourhoods $(\mathrm{N})$, regions $(\mathrm{R})$ and total sampling area $(\mathrm{T})$.

We estimated the overall allelic similarity of all pairs of samples using Nei's unbiased minimum genetic distance $\left(D_{\mathrm{m}}\right)$ (see Nei, 1987). $D_{\mathrm{m}}$ provides a measure of the net minimum number of codon

(c) The Genetical Society of Great Britain, Heredity, 78, 57-67. 
differences per locus between pairs of populations and so provides a relatively conservative measure of genetic distance (reviewed by Nei, 1987). This conservative measure was chosen partly to counter the exaggerated allele frequency variation likely to result from the clonal replication of genotypes within populations and our nonrandom selection of variable loci.

If $C$. noveazelandiae is an obligately clonal organism, then the genetic similarity of pairs of populations may be more accurately described by the similarity of their clonal composition rather than their allele frequencies. We used two approaches to test for evidence that clonal genotypes are shared among pairs of samples. First, we determined the proportion of four-locus genotypes common to each pairwise combination of samples $\left(N_{\mathrm{GS}}\right) . N_{\mathrm{GS}}$ was calculated as $2 N_{\mathrm{AB}} /\left(N_{\mathrm{A}}+N_{\mathrm{B}}\right)$, where $N_{\mathrm{AB}}$ is the number of four-locus genotypes common to samples $\mathrm{A}$ and $\mathrm{B}$, and $N_{\mathrm{A}}$ and $N_{\mathrm{B}}$ are, respectively, the number of such genotypes detected in samples $A$ and $B$. This provides an index of similarity which may vary from one (all genotypes shared) to zero (no genotypes in common) (Stoddart, 1984). We tested for the possible effects of the independent sexual production of identical four-locus genotypes by conducting the analysis twice: including all genotypes and excluding genotypes with a high probability of independent sexual origins. We excluded two genotypes (see Results) on the basis of their relatively high probability of sexual production $(P>0.10)$ in a hypothetical ancestral population. Secondly, for each four-locus genotype, we compared the number of samples in which it occurred to the number of occurrences expected in the absence of clonal sharing among samples (i.e. if samples share only four-locus genotypes that have independent sexual origins). We estimated the number of expected occurrences by assuming a hypothetical source population comprising a pooled set of all of the detected four-locus genotypes, with each genotype occurring in a frequency equal to its number of sample occurrences. We then assumed that the probability of occurrence of a given fourlocus genotype in this population, as estimated from the average allele frequencies under conditions of random mating and free recombination, was equivalent to its expected probability of occurrence in any sample. This requires that each sexually derived copy of a given four-locus genotype would occur only once within any sample and will therefore, if anything, lead to an overestimate of the number of expected sample occurrences. We then calculated, using binomial probability paper, the 95 per cent upper confidence limit of the expected number of sample occurrences.

We used two measures to assess the contribution of asexual reproduction to recruitment within each local population. First, we determined for each locus, the magnitude and direction of departures from Hardy-Weinberg equilibria. For selectively neutral alleles, asexual reproduction should generate similar numbers of deficits and excesses, although the latter are particularly indicative of clonal replication (Chaplin \& Ayre, 1989). We used $\chi^{2}$ goodness of fit tests to assess the statistical significance of departures from the expected numbers of homozygotes and heterozygotes. Secondly, we calculated the ratio of observed multilocus genotypic diversity $\left(G_{\mathrm{o}}\right)$ to that expected under conditions of sexual reproduction with free recombination and random mating $\left(G_{\mathrm{e}}\right)$ (Stoddart \& Taylor, 1988). Ratios of $G_{\mathrm{o}}$ to $G_{\mathrm{e}}$ that are less than one provide an index of the combined effects of single-locus departures from Hardy-Weinberg equilibrium and multilocus linkage disequilibria. We used unpaired $t$-tests to determine the statistical significance of differences between $G_{\text {o }}$ and $G_{\mathrm{e}}$ (Stoddart \& Taylor, 1988).

\section{Results}

\section{Allele frequency variation}

Each of the four sampled loci displayed a total of only two or three alleles over the entire sampling area (Table 1). Nevertheless, three of the four loci exhibited significant allele frequency variation among samples $(P<0.001$; Tables 1 and 2$)$. The remaining locus (Gpi) was variable in only four of the 42 samples (Table 1).

The extensive variation in allele frequencies among samples was reflected by high $F_{\mathrm{ST}}$ values, which ranged from 0.154 for $G p i$ to 0.312 for $M p i$ (Table 2). However, we found no evidence of regional pattern in this variation $\left(F_{\mathrm{RT}}=0.00\right.$; Table $2)$. Instead, 84 per cent of the total variation was detected within neighbourhoods $\left(F_{\mathrm{SN}}=0.19\right)$ and the remaining 16 per cent was the result of variation within regions (Table 2).

\section{Genotypic variation}

Evidence of clonal population structures We found strong evidence that each of the 42 sampled populations of $C$. novaezelandiae is maintained by parthenogenetic (asexual) reproduction. Samples from these populations contained more than 2255 adult females but no adult males. Individual samples 
Table 1 Allele frequency variation at four allozyme loci for each of 42 samples of Candonocypris noveazelandiae from four geographical regions in south-eastern Australia

\begin{tabular}{|c|c|c|c|c|c|c|c|c|c|c|c|c|}
\hline \multirow{2}{*}{$\begin{array}{l}\text { Region/ } \\
\text { Population }\end{array}$} & \multirow[b]{2}{*}{$N$} & \multicolumn{2}{|c|}{$G p i$} & \multicolumn{3}{|c|}{$A p k$} & \multicolumn{3}{|c|}{$P g m$} & \multicolumn{3}{|c|}{$M p i$} \\
\hline & & 100 & 89 & 138 & 100 & 74 & 111 & 100 & 89 & 126 & 108 & 100 \\
\hline Camperdown & 5 populations & & & & & & & & & & & \\
\hline $\mathrm{CD} 1$ & 52 & 1.00 & - & - & 1.00 & - & - & 1.00 & - & - & - & 1.00 \\
\hline $\mathrm{CD} 2$ & 54 & 1.00 & - & 0.31 & 0.69 & - & 0.02 & 0.98 & - & - & - & 1.00 \\
\hline CD4 & 77 & 1.00 & - & - & 0.99 & 0.01 & 0.84 & 0.16 & - & - & 0.69 & 0.31 \\
\hline Lake Purrumbete & 39 & 1.00 & - & - & 1.00 & - & 0.33 & 0.56 & 0.10 & - & 0.12 & 0.89 \\
\hline CD7 & 65 & 1.00 & - & 0.39 & 0.61 & - & 0.50 & 0.39 & 0.11 & - & 0.11 & 0.89 \\
\hline Mean & 57.40 & 1.00 & - & 0.14 & 0.86 & - & 0.34 & 0.62 & 0.04 & - & 0.18 & 0.82 \\
\hline Albury-Wodonga & 25 populations & & & & & & & & & & & \\
\hline AW1 & 59 & 1.00 & - & - & 0.94 & 0.06 & 0.51 & 0.49 & - & 0.07 & 0.04 & 0.89 \\
\hline AW2 & 69 & 0.90 & 0.10 & - & 1.00 & - & 0.22 & 0.68 & 0.10 & - & 0.15 & 0.85 \\
\hline AW3 & 61 & 0.79 & 0.21 & 0.30 & 0.70 & - & 0.03 & 0.95 & 0.02 & - & - & 1.00 \\
\hline AW5 & 51 & 1.00 & - & 0.22 & 0.78 & - & 0.66 & 0.34 & - & - & 0.40 & 0.60 \\
\hline AW6 & 68 & 1.00 & - & - & 1.00 & - & 0.90 & 0.10 & - & - & 0.79 & 0.21 \\
\hline AW7 & 58 & 1.00 & - & 0.01 & 0.99 & - & 0.50 & 0.50 & - & - & - & 1.00 \\
\hline AW8 & 54 & 1.00 & - & 0.01 & 0.99 & - & 0.48 & 0.52 & - & - & - & 1.00 \\
\hline AW9 & 51 & 1.00 & - & 0.11 & 0.89 & - & 0.07 & 0.92 & 0.01 & - & 0.03 & 0.97 \\
\hline AW10 & 46 & 1.00 & - & - & 1.00 & - & 0.50 & 0.50 & - & 0.05 & 0.02 & 0.92 \\
\hline AW11 & 51 & 1.00 & - & 0.25 & 0.75 & - & 0.59 & 0.41 & - & 0.01 & 0.20 & 0.79 \\
\hline AW12 & 65 & 1.00 & - & 0.28 & 0.72 & - & 0.51 & 0.49 & - & - & 0.18 & 0.82 \\
\hline AW13 & 53 & 1.00 & - & 0.28 & 0.67 & 0.05 & 0.58 & 0.42 & - & 0.05 & 0.15 & 0.80 \\
\hline AW14 & 65 & 1.00 & - & 0.12 & 0.88 & - & 0.66 & 0.34 & - & - & 0.40 & 0.60 \\
\hline AW15 & 53 & 1.00 & - & 0.33 & 0.67 & - & 0.55 & 0.45 & - & 0.01 & 0.19 & 0.80 \\
\hline AW16 & 51 & 1.00 & - & 0.98 & 0.02 & - & 0.91 & 0.09 & - & 0.02 & 0.84 & 0.14 \\
\hline AW17 & 54 & 1.00 & - & - & 1.00 & - & 0.52 & 0.48 & - & 0.10 & 0.06 & 0.84 \\
\hline AW18 & 58 & 1.00 & - & 0.12 & 0.88 & - & 0.63 & 0.37 & - & 0.02 & 0.27 & 0.72 \\
\hline AW19 & 54 & 1.00 & - & 0.02 & 0.98 & - & 0.49 & 0.50 & 0.01 & - & 0.08 & 0.92 \\
\hline AW20 & 56 & 1.00 & - & 0.41 & 0.59 & - & 0.54 & 0.46 & - & - & 一 & 1.00 \\
\hline AW21 & 69 & 1.00 & - & - & 1.00 & - & 0.14 & 0.86 & - & - & - & 1.00 \\
\hline AW22 & 38 & 0.82 & 0.18 & 0.07 & 0.93 & - & 0.18 & 0.82 & - & 0.09 & 0.09 & 0.82 \\
\hline AW23 & 60 & 1.00 & - & 0.13 & 0.74 & 0.13 & 0.41 & 0.53 & 0.07 & 0.18 & 0.02 & 0.80 \\
\hline AW24 & 50 & 1.00 & - & 0.41 & 0.59 & - & 0.18 & 0.80 & 0.02 & - & - & 1.00 \\
\hline AW25 & 37 & 1.00 & - & - & 1.00 & - & 0.50 & 0.50 & - & - & - & 1.00 \\
\hline AW26 & 59 & 0.98 & 0.03 & 0.14 & 0.82 & 0.04 & 0.24 & 0.61 & 0.15 & 0.07 & - & 0.93 \\
\hline Mean & 55.60 & 0.98 & 0.02 & 0.17 & 0.82 & 0.01 & 0.46 & 0.53 & 0.02 & 0.03 & 0.19 & 0.78 \\
\hline Illawarra inland & 7 populations & & & & & & & & & & & \\
\hline II1 & 31 & 1.00 & - & 0.40 & 0.60 & - & 0.07 & 0.94 & - & - & - & 1.00 \\
\hline Welby Reservoir & 50 & 1.00 & - & 0.31 & 0.69 & - & - & 1.00 & - & - & - & 1.00 \\
\hline II 4 & 53 & 1.00 & - & - & 1.00 & - & 0.51 & 0.49 & - & - & 0.03 & 0.97 \\
\hline II5 & 52 & 1.00 & - & 0.50 & 0.50 & - & 0.50 & 0.50 & - & - & - & 1.00 \\
\hline II6 & 41 & 1.00 & - & - & 1.00 & - & 0.50 & 0.50 & - & - & - & 1.00 \\
\hline II7 & 53 & 1.00 & - & - & 1.00 & - & 0.50 & 0.50 & - & - & 0.19 & 0.81 \\
\hline II8 & 59 & 1.00 & - & - & 1.00 & - & 0.50 & 0.50 & - & - & 0.29 & 0.71 \\
\hline Mean & 48.43 & 1.00 & - & 0.17 & 0.83 & - & 0.37 & 0.63 & - & - & 0.07 & 0.93 \\
\hline Illawarra coastal & 5 populations & & & & & & & & & & & \\
\hline IC1 & 52 & 1.00 & - & - & 1.00 & - & 0.50 & 0.50 & - & - & 0.48 & 0.52 \\
\hline IC2 & 52 & 1.00 & - & - & 1.00 & - & 0.50 & 0.50 & - & - & 0.50 & 0.50 \\
\hline IC4 & 38 & 1.00 & - & 0.26 & 0.53 & 0.21 & 0.50 & 0.50 & - & 0.29 & 0.11 & 0.61 \\
\hline IC5 & 57 & 1.00 & - & 0.11 & 0.71 & 0.18 & 0.51 & 0.49 & - & 0.34 & - & 0.66 \\
\hline IC6 & 40 & 1.00 & - & 0.06 & 0.88 & 0.06 & 0.50 & 0.50 & - & 0.09 & 0.24 & 0.68 \\
\hline Mean & 47.80 & 1.00 & - & 0.09 & 0.82 & 0.09 & 0.50 & 0.50 & - & 0.14 & 0.26 & 0.59 \\
\hline
\end{tabular}

-: allele absent from sample.

(c) The Genetical Society of Great Britain, Heredity, 78, 57-67. 
Table 2 Hierarchical $F_{\mathrm{ST}}$ analysis of allele frequency divergence for 42 samples of Candonocypris novaezelandiae. The hierarchy reflects the sampling of populations that are distributed among four geographical regions in southeastern Australia and that sometimes form neighbourhood groupings within regions (see Fig. 1). Chi-square analysis was used to test for statistically significant allele frequency variation among samples. $P$ is the probability of obtaining the observed $\chi^{2}$-values by chance, if allele frequencies do not differ among populations (for each test, d.f. $=41$ )

\begin{tabular}{lccccc}
\hline \multicolumn{5}{c}{} & \multicolumn{5}{c}{ Differentiation among } & \\
\cline { 2 - 5 } Locus & $\begin{array}{c}\text { Populations } \\
\text { within } \\
\text { neighbourhoods }\end{array}$ & $\begin{array}{c}\text { Populations } \\
\text { within } \\
\text { regions }\end{array}$ & Regions & $\begin{array}{c}\text { All local } \\
\text { populations }\end{array}$ & $\chi^{2}(P)$ \\
\hline$G p i$ & 0.035 & 0.165 & 0.000 & 0.154 & - \\
Apk & 0.166 & 0.208 & 0.000 & 0.194 & $\begin{array}{c}1301.97 \\
(<0.001)\end{array}$ \\
Pgm & 0.082 & 0.209 & 0.000 & 0.196 & $\begin{array}{c}933.70 \\
(<0.001)\end{array}$ \\
Mpi & 0.358 & 0.303 & 0.014 & 0.312 & $\begin{array}{c}1436.48 \\
(<0.001)\end{array}$ \\
$\begin{array}{l}\text { Mean } \\
\begin{array}{l}\text { Percentage } \\
\text { contribution } \\
\text { to total }\end{array}\end{array}$ & 0.191 & 0.234 & 0.000 & 0.228 & \\
\hline
\end{tabular}

-: Analysis was not conducted because of low levels of variation.

of between 31 and 77 females displayed few multilocus genotypes (mean $=4.05$, range $1-10$ ), many of which were highly replicated (Table 3 ). Consequently, significant departures from Hardy-Weinberg equilibrium were common, with 37 of 42 samples showing a significant excess of either homozygotes or heterozygotes for at least one locus (Table 3). Overail, 53 of a total of 91 single-locus comparisons yielded significant departures from Hardy-Weinberg expectations, with most of these (83 per cent) resulting from an excess of heterozygotes. These departures, together with the widespread occurrence of multilocus linkage disequilibria, were reflected by low levels of observed genotypic diversity (mean $=2.35$, range 1-7.12; Table 3). Moreover, all of the 39 genetically variable samples showed highly significantly less diversity than would be expected if they had been sexually derived $\left(G_{\mathrm{o}}: G_{\mathrm{e}}\right.$ less than $1 ; P<0.001$; Table 3).

Geographical variation We detected between one and 10 putative clones (i.e. distinct four-locus genotypes) within individual samples of $C$. novaezelandiae (Table 3). However, as we sampled only a minute portion of the genome, the actual number of genetically distinct individuals (i.e. true clones) present within samples may have been greater (Chaplin, 1991).

Although individual samples contained as many as ten distinct four-locus genotypes, the combined total for the 42 samples was only 26 genotypes (Table 4 ). Many (13) of the 26 genotypes were restricted to just one or two samples (Table 4). However, each of six widespread genotypes occurred in no fewer than 30 per cent of samples and three of the four sampling regions (Table 4). In combination, these six genotypes accounted for more than 88 per cent of individuals assayed. The multiple occurrences of these and other genotypes resulted in pairs of samples sharing an average of 37 per cent of their genotypes, with most pairs (85 per cent) having at least one genotype in common. Nevertheless, we found little evidence of a relationship between the geographical location and genotypic composition of local populations. Rather, the proportion of genotypes shared between samples was only weakly correlated with large-scale geographical separation (Fig. 2). These data, together with the highly clonal structure of local samples, imply that $C$. novaeze- 
Table 3 Patterns of genotypic diversity within 42 samples of $N$ adults of Candonocypris novaezelandiae. For each sample, $N_{\mathrm{g}}$ is the number of detected four-locus genotypes and $N_{\mathrm{e}}$ is the number of four-locus genotypes expected under conditions of outcrossed sexual reproduction. The level of genotypic diversity observed for each sample $\left(G_{\mathrm{o}}\right)$ is compared to the level expected for outcrossed sexual reproduction $\left(G_{e}\right) . P$ is the probability of obtaining the observed values of $G_{\mathrm{o}}: G_{\mathrm{e}}$ by chance, if populations are maintained by outcrossed sexual reproduction. For each sample, departures from Hardy-Weinberg equilibrium are summarized in terms of the number of loci showing significant $(P<0.05)$ departures (numerator) and the number of variable loci (denominator)*

\begin{tabular}{|c|c|c|c|c|c|c|c|}
\hline Population & $N$ & $N_{\mathrm{g}}$ & $N_{\mathrm{e}}$ & $G_{\mathrm{o}}$ & $G_{\mathrm{a}}: G_{\mathrm{e}}$ & $P$ & $\begin{array}{l}\text { Departures } \\
\text { from } \mathrm{H}-\mathrm{W} \dagger\end{array}$ \\
\hline CD1 & 52 & 1 & - & - & - & - & $0 / 0$ \\
\hline CD2 & 54 & 3 & 4 & 2.07 & 0.83 & $<0.001$ & $1 / 1$ \\
\hline CD4 & 77 & 5 & 8 & 1.93 & 0.47 & $<0.001$ & $1 / 2$ \\
\hline \multicolumn{5}{|l|}{ Lake } & & & \\
\hline CD7 & 65 & 2 & 21 & 1.51 & 0.12 & $<0.001$ & $2 / 3$ \\
\hline AWl & 59 & 6 & 12 & 1.68 & 0.35 & $<0.001$ & $1 / 3$ \\
\hline AW2 & 69 & 5 & 16 & 4.60 & 0.66 & $<0.001$ & $1 / 3$ \\
\hline AW3 & 61 & 6 & 11 & 3.64 & 0.68 & $<0.001$ & $2 / 2$ \\
\hline AW5 & 51 & 4 & 16 & 3.11 & 0.30 & $<0.001$ & $2 / 3$ \\
\hline AW6 & 68 & 2 & 5 & 1.49 & 0.53 & $<0.001$ & $1 / 2$ \\
\hline AW7 & 58 & 2 & 3 & 1.04 & 0.39 & $<0.001$ & $1 / 1$ \\
\hline AW8 & 54 & 3 & 3 & 1.08 & 0.40 & $<0.001$ & $1 / 1$ \\
\hline AW9 & 51 & 7 & - & - & - & - & $0 / 2$ \\
\hline AW10 & 46 & 5 & 6 & 1.51 & 0.44 & $<0.001$ & $1 / 2$ \\
\hline AW11 & 51 & 5 & 10 & 2.87 & 0.13 & $<0.001$ & $2 / 3$ \\
\hline AW12 & 65 & 4 & 16 & 2.29 & 0.24 & $<0.001$ & $2 / 3$ \\
\hline AW13 & 53 & 7 & 21 & 2.80 & 0.23 & $<0.001$ & $3 / 3$ \\
\hline AW14 & 65 & 5 & 15 & 3.44 & 0.40 & $<0.001$ & $2 / 3$ \\
\hline AW15 & 53 & 5 & 17 & 2.61 & 0.25 & $<0.001$ & $3 / 3$ \\
\hline AW16 & 51 & 4 & 7 & 1.45 & 0.56 & $<0.001$ & $1 / 2$ \\
\hline AW17 & 54 & 4 & 9 & 1.77 & 0.39 & $<0.001$ & $1 / 2$ \\
\hline AW18 & 58 & 6 & 15 & 3.05 & 0.37 & $<0.001$ & $2 / 3$ \\
\hline AW19 & 54 & 4 & 8 & 1.58 & 0.41 & $<0.001$ & $1 / 2$ \\
\hline AW20 & 56 & 4 & 8 & 1.51 & 0.24 & $<0.001$ & $2 / 2$ \\
\hline AW21 & 69 & 2 & - & - & - & - & $0 / 1$ \\
\hline AW22 & 38 & 5 & 15 & 4.20 & 0.55 & $<0.001$ & $0 / 4$ \\
\hline AW23 & 60 & 8 & 26 & 4.57 & 0.33 & $<0.001$ & $1 / 3$ \\
\hline AW24 & 50 & 5 & 8 & 2.97 & 0.61 & $<0.001$ & $1 / 2$ \\
\hline AW25 & 37 & 1 & 3 & 1.00 & 0.39 & $<0.001$ & $1 / 1$ \\
\hline AW26 & 59 & 10 & 20 & 7.12 & 0.79 & $<0.001$ & $1 / 3$ \\
\hline II1 & 31 & 3 & 5 & 1.95 & 0.63 & $<0.001$ & $1 / 2$ \\
\hline \multicolumn{8}{|l|}{ Welby } \\
\hline Reservoir & 50 & 2 & 3 & 1.89 & 0.81 & $<0.001$ & $1 / 1$ \\
\hline II4 & 53 & 3 & 4 & 1.08 & 0.64 & $<0.001$ & $1 / 1$ \\
\hline II5 & 52 & 1 & 8 & 1.00 & 0.16 & $<0.001$ & $2 / 2$ \\
\hline II6 & 41 & 1 & 3 & 1.00 & 0.39 & $<0.001$ & $1 / 1$ \\
\hline II7 & 53 & 2 & 7 & 1.89 & 0.40 & $<0.001$ & $1 / 2$ \\
\hline II8 & 59 & 2 & 8 & 1.96 & 0.35 & $<0.001$ & $2 / 2$ \\
\hline IC1 & 52 & 2 & 8 & 1.08 & 0.17 & $<0.001$ & $2 / 2$ \\
\hline IC2 & 52 & 1 & 8 & 1.00 & 0.16 & $<0.001$ & $2 / 2$ \\
\hline IC4 & 38 & 7 & 26 & 4.85 & 0.24 & $<0.001$ & $1 / 3$ \\
\hline IC5 & 57 & 6 & 23 & 3.49 & 0.24 & $<0.001$ & $1 / 3$ \\
\hline IC6 & 40 & 6 & 17 & 2.78 & 0.27 & $<0.001$ & $1 / 3$ \\
\hline
\end{tabular}

${ }^{*}$ Loci were considered variable if the frequency of the most common allele was less than 0.95 .

$\dagger$ Departures from Hardy-Weinberg equilibrium expectations.

-:parameter not calculated because of low levels of variation at all sampled loci (see Table 1).

(c) The Genetical Society of Great Britain, Heredity, 78, 57-67. 
Table 4 The number of individuals and sample occurrences together with the regional distribution of each of 26 four-locus genotypes detected from 42 samples of Candonocypris novaezelandiae. Those genotypes indicated with an asterisk occurred in more samples than would be expected if samples share only four-locus genotypes with independent sexual origins. Key to regions: $\mathrm{CD}$, Camperdown; AW, Albury-Wodonga; II, Illawarra inland; IC, Illawarra coastal

\begin{tabular}{|c|c|c|c|c|c|c|c|c|c|c|}
\hline \multirow{2}{*}{$\begin{array}{l}\text { Genotype } \\
\text { code }\end{array}$} & \multicolumn{4}{|c|}{$\begin{array}{l}\text { Four-locus genotype } \\
\text { Enzyme locus }\end{array}$} & \multirow{2}{*}{$\begin{array}{l}\text { Number of } \\
\text { individuals } \\
\text { (total }=2255 \text { ) }\end{array}$} & \multirow{2}{*}{$\begin{array}{l}\text { Number of } \\
\text { sample } \\
\text { occurrences } \\
\text { (maximum } \\
\text { possible }=42 \text { ) }\end{array}$} & \multicolumn{4}{|c|}{ Region } \\
\hline & Gpi & Apk & $P g m$ & $M p i$ & & & $\mathrm{CD}$ & AW & II & IC \\
\hline 13 & $100 / 100$ & $100 / 100$ & $111 / 100$ & $100 / 100$ & 730 & 34 & $X$ & $X$ & $X$ & $\mathrm{X}$ \\
\hline 3 & $100 / 100$ & $138 / 100$ & $111 / 100$ & $100 / 100$ & 359 & $* 20$ & $\mathrm{X}$ & $X$ & $X$ & $\mathrm{X}$ \\
\hline 12 & $100 / 100$ & $100 / 100$ & $111 / 100$ & $108 / 100$ & 270 & $* 21$ & & $X$ & $X$ & $\mathrm{X}$ \\
\hline 16 & $100 / 100$ & $100 / 100$ & $100 / 100$ & $100 / 100$ & 261 & 16 & $\mathrm{X}$ & $\mathrm{X}$ & $\mathrm{X}$ & \\
\hline 8 & $100 / 100$ & $100 / 100$ & 111/111 & $108 / 108$ & 233 & $* 13$ & $\mathrm{X}$ & $\mathrm{X}$ & $X$ & \\
\hline 5 & $100 / 100$ & $138 / 100$ & $100 / 100$ & $100 / 100$ & 143 & ${ }^{*} 13$ & $X$ & $X$ & $\mathrm{X}$ & \\
\hline 11 & $100 / 100$ & $100 / 100$ & $111 / 100$ & $126 / 100$ & 54 & 12 & & $X$ & & $\mathrm{X}$ \\
\hline 21 & $100 / 100$ & $100 / 74$ & $111 / 100$ & $126 / 100$ & 33 & $* 6$ & & $\mathrm{X}$ & & $\mathrm{X}$ \\
\hline 25 & $100 / 89$ & $100 / 100$ & $100 / 100$ & $100 / 100$ & 33 & 4 & & $X$ & & \\
\hline 7 & $100 / 100$ & $138 / 74$ & $111 / 100$ & $126 / 100$ & 29 & 3 & & & & $\mathrm{X}$ \\
\hline 18 & $100 / 100$ & $100 / 100$ & $100 / 89$ & $100 / 100$ & 24 & 3 & & $\mathrm{X}$ & & \\
\hline 14 & $100 / 100$ & $100 / 100$ & $111 / 89$ & $108 / 100$ & 22 & 2 & $X$ & & & \\
\hline 6 & $100 / 100$ & $138 / 100$ & $100 / 89$ & $100 / 100$ & 20 & 5 & & $\mathrm{X}$ & & \\
\hline 27 & $89 / 89$ & $138 / 100$ & $100 / 100$ & $100 / 100$ & 12 & 1 & & $X$ & & \\
\hline 29 & $100 / 100$ & $100 / 74$ & $111 / 100$ & $126 / 126$ & 10 & 3 & & & & $\mathrm{X}$ \\
\hline 10 & $100 / 100$ & $100 / 100$ & $111 / 111$ & $100 / 100$ & 7 & $\dagger 2$ & & $\mathrm{X}$ & & \\
\hline 9 & $100 / 100$ & $100 / 100$ & $111 / 111$ & $108 / 100$ & 3 & 2 & $\mathrm{X}$ & $\mathrm{X}$ & & \\
\hline 15 & $100 / 100$ & $100 / 100$ & $100 / 100$ & $108 / 100$ & 3 & $\dagger 2$ & $X$ & $\mathrm{X}$ & & \\
\hline 22 & $100 / 100$ & $100 / 74$ & $111 / 100$ & $100 / 100$ & 2 & 1 & & $X$ & & \\
\hline 1 & $100 / 100$ & $138 / 138$ & $111 / 100$ & $100 / 100$ & 1 & 1 & & $X$ & & \\
\hline 2 & $100 / 100$ & $138 / 100$ & $111 / 111$ & $108 / 108$ & 1 & 1 & & $X$ & & \\
\hline 19 & $100 / 100$ & $100 / 100$ & $89 / 89$ & $100 / 100$ & 1 & 1 & & $X$ & & \\
\hline 20 & $100 / 100$ & $100 / 74$ & $111 / 111$ & $108 / 100$ & 1 & 1 & $\mathrm{X}$ & & & \\
\hline 23 & $100 / 100$ & $74 / 74$ & $111 / 111$ & $126 / 126$ & 1 & 1 & & $\mathrm{X}$ & & \\
\hline 31 & $100 / 100$ & $100 / 74$ & $111 / 111$ & $126 / 126$ & 1 & 1 & & & & $\mathrm{X}$ \\
\hline 32 & $100 / 100$ & $138 / 100$ & $111 / 100$ & $108 / 100$ & 1 & $\dagger 1$ & & & & $X$ \\
\hline
\end{tabular}

$\mathrm{X}$ indicates that the genotype was found in at least one sample from the region indicated.

$\lceil$ Four-locus genotypes detected from fewer samples than expected on the basis of their predicted probability of occurrence in an hypothetical source population of the sort described in the Methods.

landiae is dominated by a few widespread groups of electrophoretically similar clones.

We used the proportion of genotypes shared by samples to assess the extent of clonal dispersal among local populations, after exclusion of two genotypes (nos 13 and 16; Table 4) that each had a relatively high probability $(P>0.10)$ of multiple sexual origins. We found that most pairs of samples (64 per cent) had at least one of the remaining genotypes in common and samples shared an average of 25 per cent of their genotypes. Moreover, the proportion of genotypes shared by pairs of samples decreased only slightly with increasing geographical separation of their source populations. This trend, however, was apparent both among regions and within the Albury-Wodonga region (other regions were not tested individually because of the small number of samples collected; Fig. 2).

To investigate further the possibility that the sharing of four-locus genotypes between samples reflects the spread of asexually derived propagules, we compared the number of sample occurrences of each four-locus genotype to the number that would be expected if samples shared only four-locus genotypes with independent sexual origins. The presence of each of five genotypes in more than the expected number of samples (Table 4) implies the occurrence of clonal dispersal. Four of these five genotypes were common and widespread (Table 4). Of the five genotypes, no. 8 provides the best evidence of clonal 


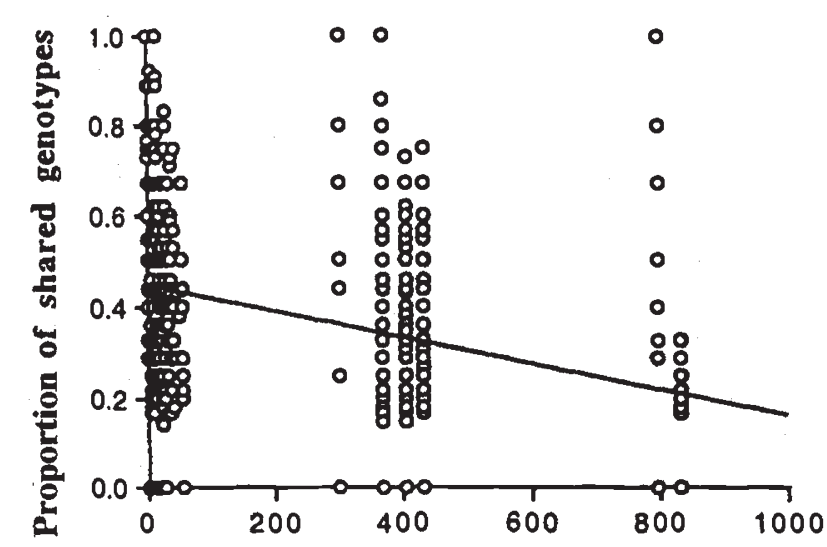

(a)
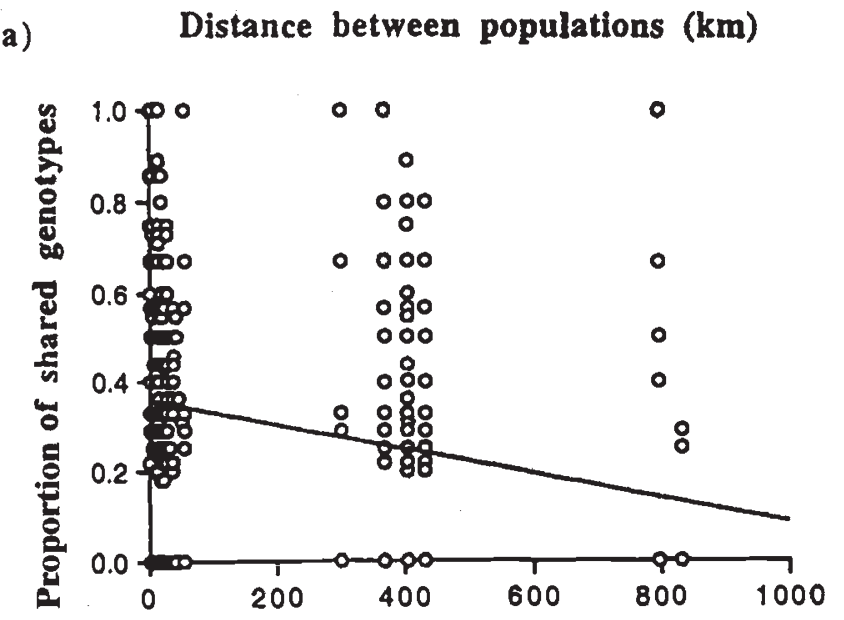

(c)

Distance between populations $(\mathrm{km})$

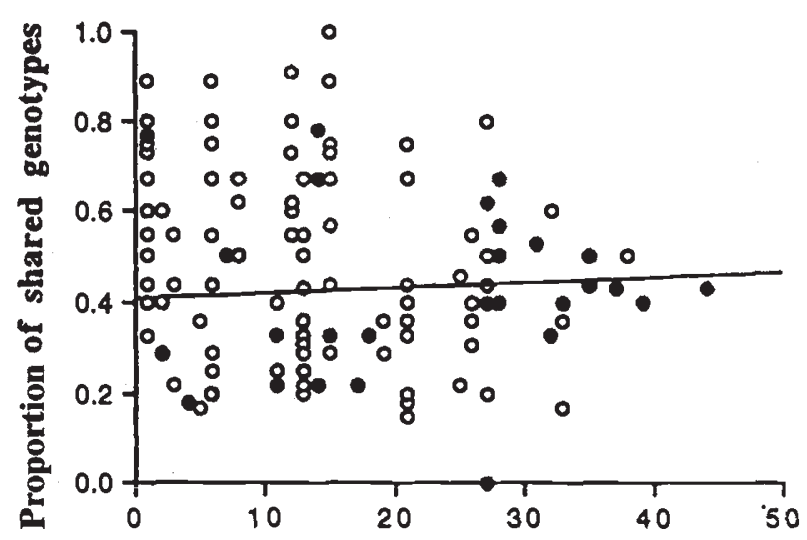

(b)

Distance between populations $(\mathrm{km})$

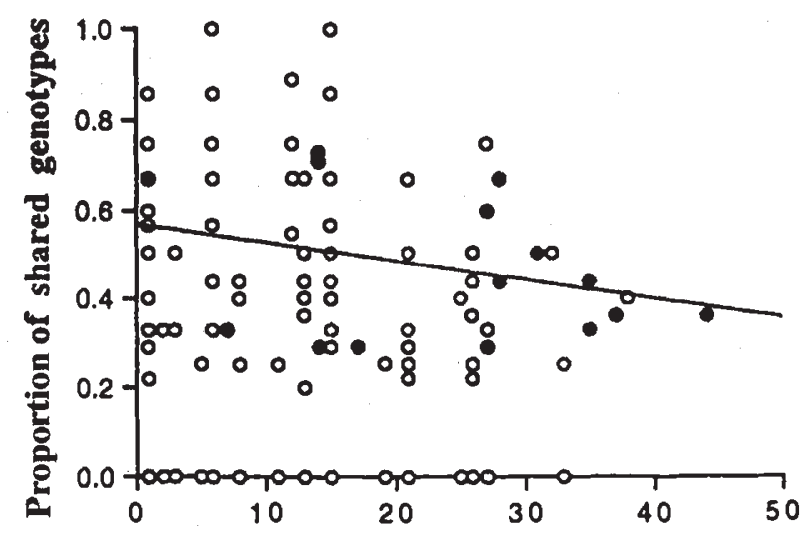

(d)

Distance between populations $(\mathrm{km})$

Fig. 2 Relationship between the proportion of distinct four-locus genotypes shared between pairs of samples of Candonocypris novaezelandiae and the distance between their source populations. Key to plots: (a) 42 samples from local populations from four geographical regions in south-eastern Australia; (b) samples from the Albury-Wodonga region comprising 17 samples from the Murray River floodplain (open circles) and eight nonfloodplain samples (solid circles); (c) and (d) as for (a) and (b), respectively, but excluding two genotypes with a high probability of independent sexual origins.

dispersal because it appeared to be unusually common at certain locations. Specifically, although this genotype was represented in a total of 13 samples, nine of the samples were from just two neighbourhoods on the floodplain of the Murray River and another two were from floodplain populations nearby to one of these neighbourhoods (Fig. 1; AW5-AW6 and AW10-AW18).

\section{Comparison of populations with and without stream connections}

Overall we found no strong evidence that stream flow is an important mediator of short- or longdistance gene flow in $C$. novaezelandiae. Indeed, both the mean genetic distance $(0.07)$ and the mean proportion of genotypes shared (36 per cent) between pairs of samples collected from the flood- plain of the Murray River were less than the corresponding values ( 0.03 and 47 per cent, respectively) for samples from the same region but from populations without any flood or stream connections. Similarly, cluster analysis of these similarity estimates indicates that samples from neighbouring populations that were joined by ephemeral streams do not consistently form homogeneous groupings on the basis of either their allelic or genotypic compositions (Chaplin, 1991). However, all of the neighbouring populations that included genotype 8 , the genotype implicated in asexual dispersal, were connected by ephemeral streams.

\section{Discussion}

The widespread distribution of the large-green morph of $C$. novaezelandiae in south-eastern Austra- 
lia appears to reflect a recent and rapid range expansion by parthenogenetic females. Certainly, neither the current study nor a previous one (Chaplin \& Ayre, 1989) revealed for this ostracod in south-eastern Australia any evidence of sexual reproduction, despite the sampling of a diversity of habitats from five geographical regions (watersheds), separated by up to $1000 \mathrm{~km}$. The observed pattern of genotypic variation clearly matched our predictions for the effects of asexually derived recruitment into local populations and is consistent with population structures reported for a range of other clonal organisms (e.g. Hoffmann, 1986; Ayre \& Willis, 1988; Hebert et al., 1988). Furthermore, the absence of males from our low diversity samples specifically implies that reproduction is by parthenogenesis. Nevertheless, we cannot exclude the possibility of rare bouts of sexual recruitment occurring in the predominantly clonal populations of this ostracod or of the existence of rare sexual populations in the sampled regions.

The south-eastern Australian population of the large-green morph of $C$. novaezelandiae is surprisingly genetically homogeneous and consequently appears to reflect the expansion of a single lineage that is now widespread throughout both natural and recently created artificial water-bodies. The virtual absence of regional differentiation, at each of four loci, implies that $C$. novaezelandiae is an effective long-distance disperser and that regions have recently been connected by high levels of homogenizing gene flow. Although we found relatively high levels of allele frequency variation within all regions, this may be explained by the stochastic differentiation of populations founded by small numbers of individuals (e.g. Boileau \& Hebert, 1991) and by variation in the abundance of clonal genotypes within local populations (e.g. Ayre \& Willis, 1988). More importantly, the extent of allele frequency variation within regions was equivalent to that detected between regions separated by up to $850 \mathrm{~km}$ and there was little evidence of fine-scale clustering of neighbouring populations, including those within a single 'floodplain' (Chaplin, 1991). Similarly, high levels of allele frequency divergence over microgeographical scales have been documented for ponddwelling species representing a range of taxa and breeding systems (e.g. Hebert \& Payne, 1985; Havel et al., 1990). Those studies that have also included macrogeographical sampling indicate that the finescale divergence is only rarely accompanied by regional differentiation (Benzie, 1986; Schwartz \& Hebert, 1987; Crease et al., 1990; Hebert et al., 1993).
If clonal genotypes are spread more readily between neighbouring rather than distant populations, then the proportion of shared genotypes should decrease with increasing geographical separation. Such a relationship has been documented for obligately parthenogenetic Daphnia pulex, for which pairs of populations less than $1 \mathrm{~km}$ apart generally share most of their clones whereas those further apart show a marked decrease in clonal similarity with increasing distance (Hebert et al., 1989). However, patterns of dispersal in pond-dwelling parthenogens are generally little known. In our study, the proportion of multilocus genotypes shared by pairs of samples decreased only slightly with increasing distance between populations and this trend was evident only over relatively large distances. These data imply that the philopatric dispersal of clones is rarely important for $C$. novaezelandiae, although the finding of one unusually common genotype (no. 8) that predominantly occurred on the Murray River floodplain and then mainly in two neighbourhoods within the floodplain provided a striking exception. It seems certain that the distribution of this multilocus genotype reflects the spread of single clones among neighbouring ponds and possibly the movement of a single clone within the floodplain.

Although we found little evidence of extensive clonal sharing among neighbouring populations of C. novaezelandiae, multilocus genotypes were shared among local populations separated by up to $850 \mathrm{~km}$. Each of two very common and widespread genotypes (nos 13 and 16) probably represent a polyphyletic group of clones and each of another five multilocus genotypes occurred in significantly more samples than would be expected in the absence of clonal dispersal. Four of the five unexpectedly common genotypes were geographically widespread and occurred in a range of different habitat types (Chaplin, 1991). The contrast between the distribution of these widespread genotypes and those of the majority of detected genotypes, which were restricted to three or fewer samples, suggests that some clones may be better colonists than others or that clones differ in their level of habitat specialization.

The hypothesized rapid range expansion by $C$. novaezelandiae into a large number of farm ponds may have been possible only because they represented vacant habitat or may reflect unusual patterns or mechanisms of dispersal. Although $C$. novaezelandiae may occasionally be dispersed by floodwaters (Chaplin, 1991), our study indicated that neither major nor minor stream flow are particularly 
important in its dispersal. De Deckker (1977) has argued that the current distribution of some Australian Ostracoda has been greatly influenced by the migration paths of waterfowl and historically waterfowl and other birds may have been crucial to the spread of $C$. novaezelandiae. More recently, agricultural activities have probably become the major influence as $C$. novaezelandiae, with its desiccationresistant eggs and capacity for torpor (Chaplin, 1991), must be commonly transported both shortand long-distances on the bodies of farm animals. Moreover, farm ponds, which are exceedingly common and widespread in south-eastern Australia, probably serve as 'stepping-stones' and may greatly augment long-distance dispersal in this ostracod.

\section{Acknowledgments}

The generous encouragement and financial support supplied by the Murray-Darling Freshwater Research Centre is gratefully acknowledged, as is the financial support provided by the University of Wollongong. We thank Jim Stoddart for providing the computer program to calculate $G_{\mathrm{e}}$ and Patrick De Deckker for advice concerning ostracod biology. Finally, J.A.C. thanks Rufus, her favourite field companion.

\section{References}

AYRE, D. J. AND willis, B. L. 1988. Population structure in the coral Pavona cactus: clonal genotypes show little phenotypic plasticity. Mar. Biol., 99, 495-505.

BENZIE, J. A. H. 1986. The ecological genetics of freshwater zooplankton in Australia. In: De Deckker, P. and Williams, W. D. (eds) Limnology in Australia, pp. 175-191. CSIRO, Melbourne.

BOILEAU, M. G. AND HEBERT, P. D. N. 1991. Genetic consequences of passive dispersal in pond-dwelling copepods. Evolution, 45, 721-733.

CARBONEL, P., COLIN, J.-P., DANIELOPOL, D.L., LÖFFLER, H. AND Neustrueva, 1. 1988. Palaeoecology of limnic ostracodes: a review of some major topics. Palaeogeog., Palaeoclim., Palaeoecol., 62, 413-461.

CHAPLIN, J. A. 1991. The Effects of Reproduction and Dispersal on the Population Structure of a Freshwater Ostracod. Ph.D. Thesis, University of Wollongong, Australia.

CHAPLIN, J. A. 1992. Variation in the mode of reproduction among individuals of the freshwater ostracod Candonocypris novaezelandiae. Heredity, 68, 411-424.

CHAPLIN, J. A. AND AYRE, D. J. 1989. Genetic evidence of variation in the contributions of sexual and asexual reproduction to populations of the freshwater ostracod Candonocypris novaezelandiae. Freshwater Biol., 22, 275-284.

CREASE, T. J., LYNCH, M. AND SPITZE, K. 1990. Hierarchical analysis of population genetic variation in mitochondrial and nuclear genes of Daphnia pulex. Mol. Biol. Evol., 7, 444-458.

DE DECKKER, P. 1977. The distribution of the 'giant' ostracods (Family Cyprididae Baird, 1845) endemic to Australia. In: Löffler, H. and Danielopol, D. (eds) Aspects of the Ecology and Zoogeography of Recent and Fossil Ostracoda, pp. 285-294. Junk, The Hague.

HAVEL, J. E., HEBERT, P. D. N. AND DELORME, L. D. 1990. Genetics of sexual Ostracoda from a low Arctic site. $J$. Evol. Biol., 3, 65-84.

HEBERT, P. D. N. 1987. Genotypic characteristics of the Cladocera. Hydrobiologia, 145, 183-193.

HEBERT, P. D. N. AND PAYNE, w. J. 1985. Genetic variation in populations of the hermaphroditic flatworm Mesostoma lingua (Turbellaria, Rhabdocoela). Biol. Bull., 169, 143-151.

HEBERT, P. D. N., WARD, R. D. AND WEIDER L. J. 1988. Clonal-diversity patterns and breeding-system variation in Daphnia pulex, an asexual-sexual complex. Evolution, 42, 147-159.

HEBERT, P. D. N., BEATON, M. J., SCHWARTZ, S. S. AND STANTON, D. J. 1989. Polyphyletic origins of asexuality in Daphnia pulex. I. Breeding-system variation and levels of clonal diversity. Evolution, 43, 1004-1015.

HEBERT, P. D. N., SCHWARTZ, S. S., WARD, R. D. AND FINSTON, T. L. 1993. Macrogeographic patterns of breeding system diversity in the Daphnia pulex group. I. Breeding systems of Canadian populations. Heredity, $\mathbf{7 0}$, 148-161.

HOFFMANN, R. J. 1986. Variation in the contribution of asexual reproduction to the genetic structure of populations of the sea anemone Metridium senile. Evolution, 40, 357-365.

NEI, M. 1987. Molecular Evolutionary Genetics. Columbia University Press, New York.

PROCTOR, v. w. 1964. Viability of crustacean eggs recovered from ducks. Ecology, 45, 656-658.

SCHWARTZ, S. S. AND HEBERT, P. D. N. 1987. Breeding system of Daphniopsis ephemeralis: adaptations to a transient environment. Hydrobiologia, 145, 195-200.

stODDART, J. A. 1984. Genetic differentiation amongst populations of the coral Pocillopora damicornis off Southwestern Australia. Coral Reefs, 3, 149-156.

STODDART, J. A. AND TAYLOR, J. F. 1988. Genotypic diversity: estimation and prediction. Genetics, 118, 705-711.

wILSON, C. C. AND HEBERT, P. D. N. 1992. The maintenance of taxon diversity in an asexual assemblage: an experimental analysis. Ecology, 73, 1462-1472.

WRIGHT, s. 1978. Evolution and the Genetics of Populations, vol. 4, Variability Within and Among Natural Populations. University of Chicago Press, Chicago. 